\title{
MICOBIOTA AISLADA DE SERPIENTES EN CUARENTENA DEL CENTRO PARA INVESTIGACIONES Y RESPUESTAS EN OFIDIOLOGÍA DE LA UNIVERSIDAD DE PANAMÁ (CEREO)
}

\author{
Javier Mancilla ${ }^{1,2}$ (D) , Migdalia Mora ${ }^{3}$ (D) , Dalila Del Carmen \\ Montañez $^{2,4}$ (iD , Víctor Martínez ${ }^{5}$ (iD , Rogemif Fuentes ${ }^{6}$ \\ Raúl Carranza ${ }^{3}$
}

${ }^{1}$ Universidad Especializada de las Américas, Facultad de Biociencias y Salud Pública. Edificio 850, Albrook Panamá. ${ }^{2}$ Universidad de Panamá, Departamento de Microbiología y Parasitología ${ }^{3}$ Departamento de Ciencias Ambientales, Universidad de Panamá. ${ }^{4}$ Centro de Estudio de Recursos Bióticos (CEREB), Universidad de Panamá, ${ }^{5}$ Centro para Investigaciones y Respuestas en Ofidiología (CEREO), Universidad de Panamá ${ }^{6}$ Los Naturalistas, P.O. Box 0426-01459, David, Chiriquí, Panamá E-mail: javier.mancilla@udelas.ac.pa, migdamora@hotmail.com, ORCID_prof.dalmontz.up@gmail.com; pvmartinez@gmail.com; rogermifdaniel@gmail.com; raulcarranza@up.ac.pa, Autor de correspondencia: Dalila Montañez.

\section{RESUMEN.}

Las serpientes al igual que los hongos, son organismos que a lo largo del tiempo han sido estigmatizados, no permitiendo con ello conocer y valorar su rol en los procesos biológicos en los cuales intervienen. Esta investigación tuvo como propósito, determinar los principales grupos de hongos filamentosos que cohabitan con las serpientes en cuarentena en el Centro para Investigaciones y Respuestas en Ofidiología de la Universidad de Panamá (CEREO). La misma, fue realizada teniendo como sujetos de estudio, 9 serpientes pertenecientes a diversos géneros, que se encontraban en periodo de cuarentena, a dicha muestra se le realizó un análisis micológico, utilizando técnicas de microbiología clásica, basando el reconocimiento de los géneros encontrados en comparaciones morfológicas. El análisis de la micobiota de las serpientes en cuarentena en el CEREO pretende como objetivo principal, establecer mediante la comparación de morfotipos aislados las principales poblaciones de hongos filamentosos que están presentes en la muestra; implementando técnicas microbiológicas (aislamiento, selección y purificación de muestras). La caracterización e identificación microscópica se realizó mediante la técnica de microcultivo en PDA, agar V8 y agar Agua, empleando las claves taxonómicas, con base en las observaciones de estructuras 180 
fúngicas y reproductivas, que permitieron la identificación sólo hasta género. Los principales grupos de hongos aislados están representados por los siguientes géneros, Penicillium, Curvularia, Aspergillus, Fusarium y Cladosporium; que son hongos típicamente encontrados en el suelo, este estudio pionero en nuestro país, sienta las bases metodológicas y procedimentales para el análisis de hongos filamentosos en ofidios y las posibles relaciones que pudiesen existir entre estos dos grupos de organismos.

PALABRAS CLAVE: ofidio, hongo, simbiosis, microbiología.

\title{
MICOBIOTA ISOLATED FROM SNAKES IN QUARANTINE OF THE CENTER FOR RESEARCH AND OFFICE RESPONSES OF THE UNIVERSITY OF PANAMA (CEREO)
}

\begin{abstract}
Snakes, like fungi, are organisms that over time have been stigmatized, thus not allowing to know and value their role in the biological processes in which they intervene. This research was intended to determine the main groups of filamentous fungi that cohabit with quarantined snakes at the Center for Research and Responses in Odiology of the University of Panama (CEREO). The same, was carried out having, as study subjects, 9 snakes belonging to various genera, which were quarantined, this sample was performed a mycological analysis, using classical microbiology techniques, based on the recognition of the genera found in morphological comparisons. The analysis of the mycobiot of quarantined snakes in CEREO is intended as the main objective, to establish by comparing isolated morphotypes the main populations of filamentous fungi that are present in the sample; implementing microbiological techniques (isolation, selection and purification of samples). The microscopic characterization and identification was performed using the microculture technique in PDA, V8 Agar and water Agar, using the taxonomic keys, based on observations of fungal and reproductive structures, which allowed identification only to gender. The main groups of isolated fungi are represented by the following genera, Penicillium, Curvularia, Aspergillus, Fusarium and Cladosporium; which are fungi typically found in soil, this pioneering study in our country lays the methodological and procedural basis for the analysis of filamentous fungi in ofidia and the possible relationships that might exist between these two groups of organisms.
\end{abstract}

KEY WORDS: ophidian, fungus, symbiosis, microbiology. 


\section{INTRODUCCIÓN.}

Para un normal y óptimo funcionamiento, los ecosistemas requieren de organismos pertenecientes a un sin número de géneros y especies diferentes; esta investigación, pionera para nuestro país, intenta sentar las bases metodológicas y experimentales para el análisis de dos grupos de organismos que a lo largo del tiempo han sido estigmatizados por los seres humanos, ofidios y hongos, y que sin duda alguna ejercen una función vital en el desarrollo de los ciclos biológicos que se efectúan día tras día; muchos de los cuales se ejecutan sin darnos cuenta.

Los microorganismos son todos los seres vivos que observamos al microscopio; los cuales son principalmente unicelulares, aunque también pueden vivir asociados, en consorcios o en estructuras multicelulares, como es el caso de muchos hongos filamentosos; son organismos eucariotas, y según la teoría endosimbiótica pertenecen a los eucariotas más antiguos, además su pequeño tamaño les permite ser esparcidos por muchos kilómetros, ya sea por el viento, agua u otros organismos logrando así colonizar a una amplia gama de ambientes. Curiel, J. (2016)

Los hongos están ampliamente distribuidos en la naturaleza, encontrándose en el suelo, la vegetación, la materia existente en el agua y en general en cualquier ambiente húmedo. En su mayoría son beneficiosos para el hombre, ya que se encargan de degradar la materia orgánica compleja convirtiéndola a formas químicas simples que pasan a formar parte del suelo, donde finalmente son absorbidas por otras generaciones de plantas, encargándose en gran medida de la fertilidad de la tierra. García, F. (2012). Pese a los perjuicios que pueden causar estos organismos a otros seres vivos, incluyendo a los humanos, son un grupo de organismos muy importantes y exitosos desde el punto de vista evolutivo trascendental para la vida en el planeta.

Por su lado los ofidios inspiran fascinación y sentimientos de una manera que ningún otro animal puede. Estos reptiles juegan un papel importante en el medio ambiente natural y la cadena alimenticia. Como cazadores eficaces y depredadores de emboscada, las serpientes usan su altamente desarrollado sentido de la vista, olfato, oído y tacto para localizar, reconocer y rastrear a su presa. Algunas serpientes utilizan una dosis letal de veneno para paralizar 
y matar a sus presas, mientras que otras utilizan sus poderosos y musculosos cuerpos para exprimir a su presa hasta la muerte.

Las serpientes son criaturas de gran movilidad, capaces de moverse sobre la arena y las rocas, madrigueras en el suelo; colarse por las grietas y hendiduras en las rocas; subir paredes verticales de rocas y trepar en las ramas de los árboles más delgados, y hasta nadar a gran velocidad, todo ello sin extremidades. Serpientepedia (2019)

En general los humanos, nos olvidamos de que las serpientes y otros reptiles constituyen una proporción significativa de los depredadores, que mantienen a nuestros ecosistemas naturales equilibrados. Sin ellos, el número de especies de presa aumentarían a niveles no naturales y los depredadores de las serpientes lucharían para encontrar alimento, con terribles consecuencias para la biodiversidad, y por supuesto, para los humanos.

Gran parte de la estructura interna de la serpiente se modifica debido a la forma del cuerpo larga y esbelta del animal. Los ofidios conocidos como serpientes son escamosos que han llevado la ausencia de patas al extremo, incluso perdiendo las cinturas escapular y pélvica en el proceso. Las distintas familias de serpientes presentan características similares en cuanto a su morfología; pero distan en sus costumbres, teniéndolas desde terrestres, pasando por arborícolas hasta la memorable Chrysopelea paradisi, la serpiente voladora. Si bien son odiadas por la mayor parte de las personas, las serpientes actúan como controladores biológicos, eliminando a los débiles y enfermos para asegurar la sobrevivencia de las especies y evitando la propagación de enfermedades. Guzmán et al, (1990) De todos los animales, las serpientes se encuentran entre las más conocidas, pero quizás las más incomprendidas; debido a que existen muchas especies venenosas, que han causado muertes y perdida de extremidades a los humanos y cabe señalar que en el caso de las no venenosas; también existe el peligro porque muchas son constrictoras capaces de apresar a su víctima, al punto de sofocarla provocándole la muerte en pocos minutos para posteriormente tragarla y digerirla. Las serpientes se encuentran en casi todas las partes del mundo, excepto en las regiones polares. Aunque la mayor diversidad de especies se encuentra en los trópicos, las mismas ocupan una amplia gama de hábitats, desde los desiertos hasta las selvas tropicales, lagos y océanos. La mayoría de las serpientes son generalmente solitarias durante la mayor parte del año. En algunas especies, grandes cantidades se congregan para el apareamiento o la hibernación. 
Las serpientes reptan, por lo tanto; estos organismos además de sus funciones en el ecosistema, como controladores de plagas en los cultivos (se alimentan de roedores), y como bioindicadores en los ecosistemas; entre otras, también pueden representar una fuente de información valiosa, que nos ayude a establecer las relaciones de simbiosis que existen entre ellas y otros grupos de organismos (este caso los hongos).

Mediante el muestreo realizado a las serpientes en cuarentena del Centro para Investigación y Respuestas en Ofidiología de la Universidad de Panamá; se aislaron ocho géneros de hongos filamentosos. En el estudio se utilizaron cuatro géneros de serpientes diferentes entre las cuales podemos señalar: Bothriechis schlegelii (5 ejemplares), Bothrops asper (3 ejemplares), Chironius carinatus (1 ejemplar) y Spilotes pullatus (1 ejemplar); totalizando un grupo de 9 individuos. Para esta investigación nos circunscribimos como objetivo principal a la identificación micológica hasta la categoría taxonómica de género, pues, aunque en la actualidad existen las herramientas tecnológicas para el logro de este objetivo hasta nivel de especie; la misma es muy costosa y excede el presupuesto designado para esta investigación.

Los hongos filamentosos se identifican a nivel de género, por la morfología del micelio, pero sobre todo por las características microscópicas de sus esporas asexuadas y los elementos que las originan. Para conseguir la producción de esporas a veces se requieren medios de cultivo especiales que facilitan la esporulación. Las estructuras reproductivas asexuadas (conidióforos) son muy frágiles y para poder observarlas al microscopio sin distorsionarlas o destruirlas se emplean técnicas especiales (microcultivo). (Piepenbring et al., 2011, p 27-40)

\section{MATERIALES Y MÉTODOS.}

Esta es una investigación cualitativa exploratoria descriptiva de corte inductivo, en la cual se definen los resultados del análisis de una unidad experimental la cual está representada por una población de serpientes en periodo de cuarentena en el Centro para Investigaciones y Respuestas en Ofidiología de la Universidad de Panamá (CEREO), en donde se describen luego de minuciosos análisis micológicos, los resultados obtenidos, los cuales determinan los principales géneros de hongos filamentosos que cohabitan en la muestra seleccionada. 
Toma de muestra.

Los especímenes objeto de esta investigación permanecían en cuarentena, durante un período de treinta días, en los cuales se realizan análisis médicos y parasitológicos y se desparasitan con ivermectina (un antihelmíntico ampliamente utilizado), con lo que se levanta una ficha clínica, adicional a esto se les suministra una alimentación basada en el consumo de un ratón cada 20 días; provenientes del Bioterio de la Facultad de Medicina Veterinaria de la Universidad de Panamá. Procedimos a obtener las muestras, en tres áreas previamente seleccionadas de la anatomía de las serpientes (dorso, vientre y cloaca); puntos donde realizamos los hisopados con material previamente esterilizado, utilizando para dicho propósito una autoclave horizontal. Dichas muestras fueron posteriormente depositadas en tubos con agua tamponada, auto clavados y debidamente rotulados. Las muestras en húmedo se conservaron a temperatura ambiente $\left(27^{\circ} \mathrm{C}-32^{\circ} \mathrm{C}\right)$ para su posterior análisis; una vez utilizadas fueron colocadas en crio preservación, para conservar la muestra en caso de algún error procedimental. Las muestras obtenidas fueron sembradas en platos Petri con agar papa dextrosa (PDA) más ácido tartárico; este último reduce el $\mathrm{pH}$ promoviendo la inhibición del crecimiento bacteriano y promoviendo el crecimiento fúngico, los platos fueron posteriormente incubados por un periodo que oscilaba entre 5 a 7 días a una temperatura que fluctuaba entre $27^{\circ} \mathrm{C}-32^{\circ} \mathrm{C}$.

Una vez obtenido el crecimiento fúngico, se separan progresivamente los géneros obtenidos mediante el proceso de purificación, hasta lograr la observación de un género específico de hongo. Dicho proceso inicia con la inoculación de cada una de las colonias fenotípicamente diferentes en tubos inclinados con PDA, una vez obtenidas las colonias, las mismas son nuevamente aisladas en platos Petri pequeños (60 X $15 \mathrm{~mm})$, para observar con más detalle las características fenotípicas propias de la colonia. Las características fenotípicas de los micelios desarrollados en sustratos o medio de cultivos sólidos; sirven para una aproximación taxonómica, en la identificación de las estructuras de los hongos. (Piepenbring et al., 2011, p 27-40)

Cabe señalar que la cantidad de muestra obtenida cumple con el teorema del límite central. El cual establece que, en condiciones muy generales, si $\mathrm{S} n$ es la suma de $n$ variables aleatorias independientes y de varianza no nula pero finita, entonces la función de distribución de $\mathrm{S} n$ «se aproxima bien» a una distribución normal 
(también llamada distribución Gaussiana, curva de Gauss o campana de Gauss). Así pues, el teorema asegura que esto ocurre cuando la suma de estas variables aleatorias e independientes es lo suficientemente grande.

\section{Análisis y caracterización de morfotipos mediante el método de microcultivos.}

Una vez obtenidos los resultados de los cultivos puros, continuamos con la confección de los microcultivos fúngicos, los cuales nos permiten observar de manera microscópica la morfología presente en cada uno de los organismos estudiados. Para tal fin, utilizamos varios medios de cultivos (agar avena, agar V8 y agar agua), tratando de establecer con esto cual o cuales, de los mismos, poseen una composición que favorezca el crecimiento de los hongos objeto de esta investigación. Es importante señalar que los agares no son considerados como tratamientos sino como réplicas de una misma muestra.

\section{Método de microcultivo}

Al cabo de tres semanas aproximadamente, luego de que se lograron reconocer macro morfológicamente los hongos aislados, se seleccionaron los aislamientos de los hongos obtenidos a partir de los tubos inclinados con PDA y se sembraron en platos Petri con PDA e incubados a temperatura ambiente $\left(27 \pm 0.2^{\circ} \mathrm{C}\right)$ durante 5 a 7 días, para la reactivación de los mismos. A partir de los hongos aislados y reactivados, se realizaron los montajes de los microcultivos fúngicos. Arenas (1993) señala: este método es el más preciso y permite observar las estructuras fúngicas in situ. Para la realización del método de microcultivo, se tomaron platos Petri de vidrio vacíos a los que se le colocó una hoja de papel toalla estéril, sobre el papel toalla un triángulo de vidrio estéril en $\mathrm{U}$, y se depositaron $5 \mathrm{ml}$ de agua estéril en el plato Petri con el fin de evitar la desecación posterior. Se trasfirieron portaobjetos estériles sobre el triángulo y con ayuda de un asa micológica se colocaron 4-5 cubos de agar (agar V8, Avena, y agar Agua de $1 \mathrm{~cm}^{2}$ aprox.) sobre el portaobjeto; luego con un asa micológica estéril se sembraron fragmentos de micelio sobre el centro y extremos del cubo de agar. Los platos Petri son sellados finalmente con parafilm e incubados a temperatura ambiente $\left(27 \pm 0.2^{\circ} \mathrm{C}\right)$ durante 5 a 7 días (Casas, 1989; Arenas, 2003; Arenas, 2008) (p.352). En este trabajo, el triángulo de vidrio estéril se reemplazó por dos portaobjetos estériles, sobre los cuales se colocaron transversalmente un tercer portaobjeto estéril, que a su vez sostuvieron los cubos de agar inoculados y cubiertos 
por los cubreobjetos estériles Este arreglo creó un ambiente propicio para el crecimiento del hongo.

\section{RESULTADOS.}

Los resultados demuestran una estrecha correlación porcentual entre los hongos típicamente encontrados en el suelo y la micobiota presente en los ofidios estudiados. Del total de muestras tomadas (3 réplicas por área y por individuo) se lograron aislar un total de 144 individuos, los cuales mostraron prevalencia en crecimiento en el medio de cultivo PDA. Bills et al., (2004) señala en este sentido "Los hongos prosperan principalmente por el medio usado", razón por la cual dentro de los resultados también podemos observar un número importante de representantes (12 en total) de la especie Micelia esterilia, la cual ha reportado en investigaciones previas su aparición cuando el medio de cultivo no cumple con los requerimientos nutricionales de la especie. (p.777)

Dichos hallazgos fueron estadísticamente analizados utilizando el diseño de bloques, los tratamientos son los estratos (dorso, vientre y cloaca), mientras que los bloques son las especies de las serpientes, para este propósito se utilizó la herramienta estadística Statistical Package for the Social Sciences (SPSS) de la IBM, misma la cual permitió el análisis y la correlación de los resultados obtenidos.

El cuadro número 1, evidencia los resultados porcentuales de los organismos y áreas donde los mismos prevalecen adicional a las principales especies encontradas en el estudio. Por su parte los gráficos 1 y 2 , señalan la abundancia porcentual de los organismos encontrados, mismos que están correlacionados por el área de la serpiente en la cual fueron ubicados. 
Cuadro 1. Principales géneros de hongos filamentosos encontrados en el muestreo realizado a las serpientes en cuarentena del CEREO (las siglas D representa el área del dorso, la $\mathrm{V}$, el vientre y la $\mathrm{C}$, la cloaca).

\begin{tabular}{|c|c|c|c|c|c|c|c|c|c|c|c|c|c|}
\hline & & \multicolumn{3}{|c|}{ Spilotes } & \multicolumn{3}{|c|}{ Chironius } & \multicolumn{3}{c|}{ Botriechis } & \multicolumn{3}{|c|}{ Bothrops } \\
\hline $\begin{array}{c}\text { Géneros de } \\
\text { hongos } \\
\text { encontrados }\end{array}$ & & D & V & C & D & V & C & D & V & C & D & V & C \\
\hline Penicillium & 111 & 2 & 9 & 8 & 4 & 12 & 7 & 6 & 18 & 10 & 6 & 18 & 11 \\
\hline Aspergillus & 3 & 0 & 0 & 0 & 0 & 0 & 0 & 0 & 1 & 0 & 0 & 2 & 0 \\
\hline Micelia esterilia & 12 & 0 & 2 & 0 & 0 & 2 & 0 & 1 & 2 & 2 & 0 & 2 & 1 \\
\hline Curvularia & 6 & 0 & 0 & 0 & 0 & 0 & 0 & 0 & 1 & 1 & 0 & 3 & 1 \\
\hline Fusarium & 3 & 0 & 0 & 0 & 0 & 0 & 0 & 0 & 1 & 0 & 0 & 1 & 1 \\
\hline Geotrichium & 3 & 0 & 0 & 0 & 0 & 1 & 0 & 0 & 1 & 0 & 0 & 1 & 0 \\
\hline Pythium & 3 & 0 & 0 & 0 & 0 & 0 & 0 & 0 & 0 & 0 & 0 & 2 & 1 \\
\hline Cladosporium & 3 & 0 & 0 & 0 & 0 & 0 & 0 & 0 & 0 & 1 & 0 & 0 & 2 \\
\hline Total, general & 144 & 2 & 11 & 8 & 4 & 15 & 7 & 7 & 24 & 14 & 6 & 29 & 17 \\
\hline
\end{tabular}

Fuente. Datos obtenidos en investigación.

Gráfico $\mathrm{N}^{\circ} 1$. Distribución porcentual de hongos filamentosos encontrados en el muestreo realizado a las serpientes en cuarentena del CEREO.

\section{Distribución porcentual de especies aisladas}

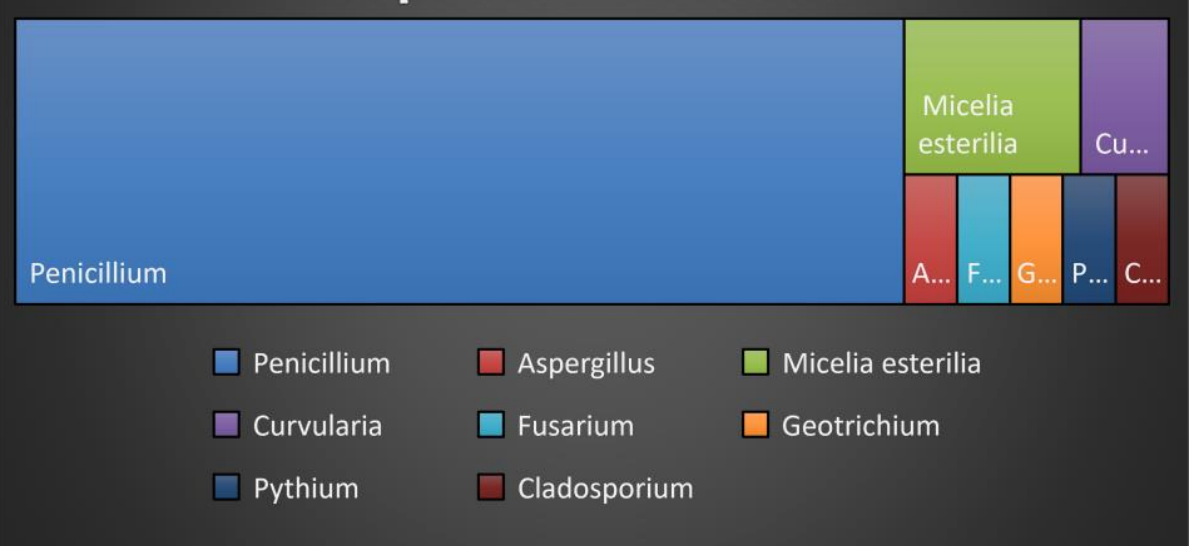

Fuente. Datos obtenidos en investigación, expresados en cuadro $\mathrm{N}^{\circ} 1$. 
Gráfico $\mathrm{N}^{\circ} 2$. Distribución porcentual de hongos filamentosos encontrados en el muestreo, compara especies y distribución por área.

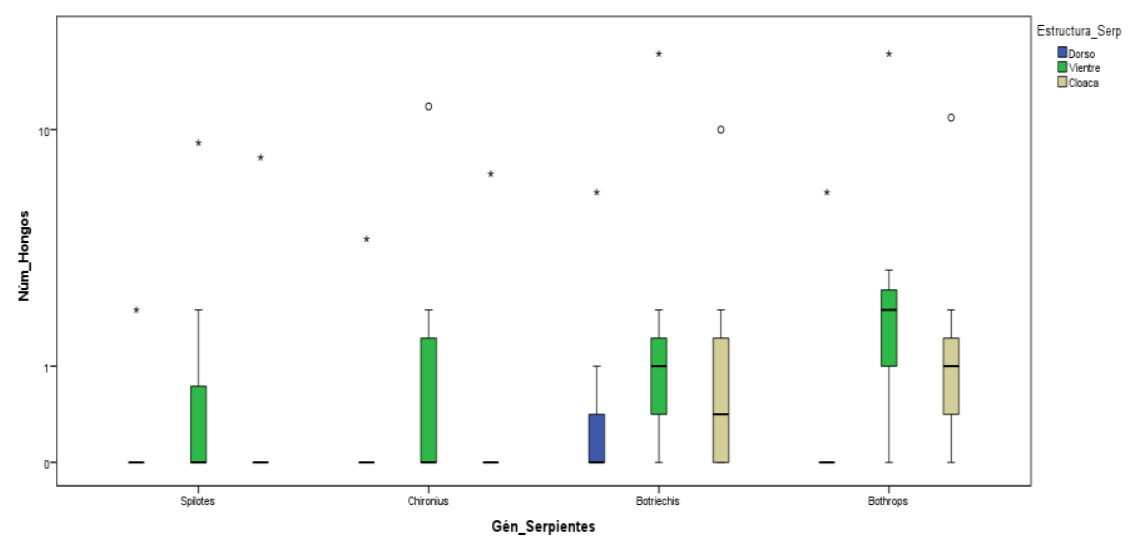

Fuente. Datos obtenidos en investigación, expresados en cuadro $\mathrm{N}^{\circ} 1$.

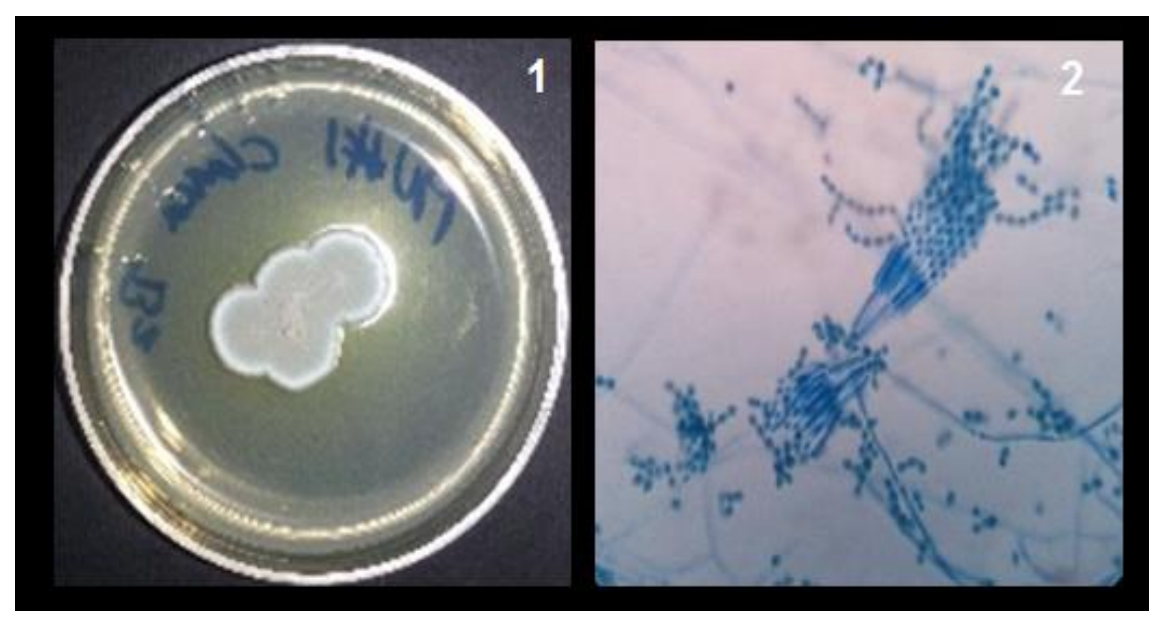

Fig. 1. Morfotipo macroscópico obtenido en medio de cultivo PDA de uno de los tres géneros predominantes, Penicillium

Fig. 2. Morfotipo microscópico obtenido en medio de cultivo PDA (luego del proceso de purificación de la muestra mediante el crecimiento en microcultivo) de uno de los tres géneros predominantes, Penicillium 


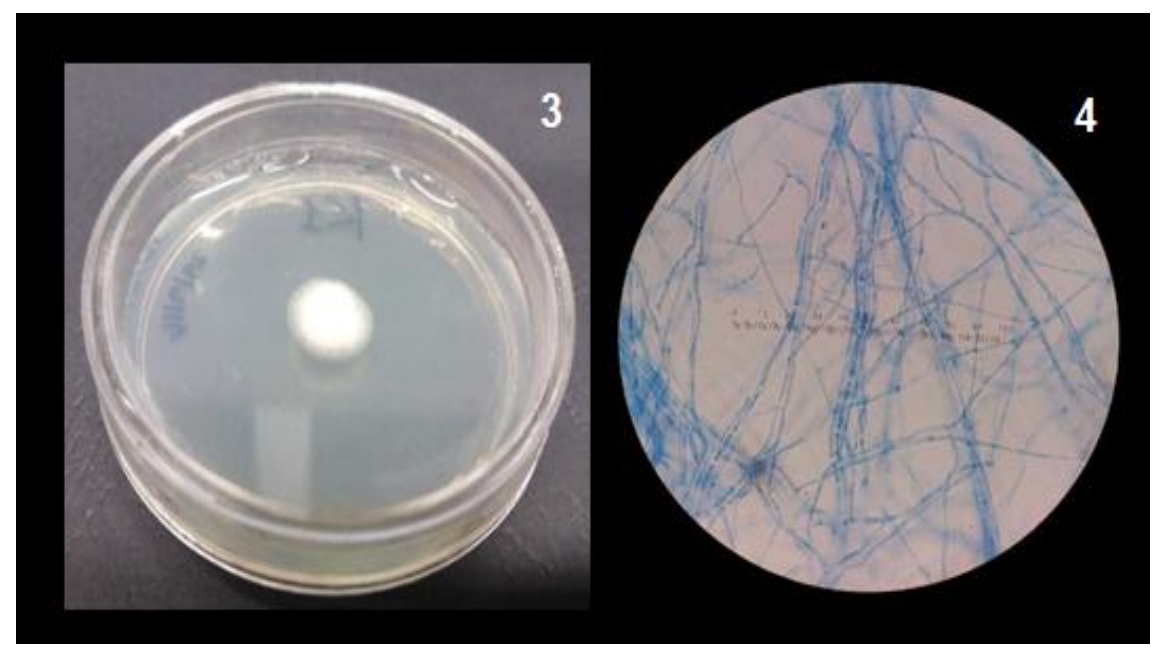

Fig. 3. Morfotipo macroscópico obtenido en medio de cultivo PDA de uno de los tres géneros más representativos, Micelio esterilia.

Fig. 4. Morfotipo microscópico obtenido en medio de cultivo PDA (luego del proceso de purificación de la muestra mediante el crecimiento en microcultivo) de uno de los tres géneros más representativos, Micelio esterilia.

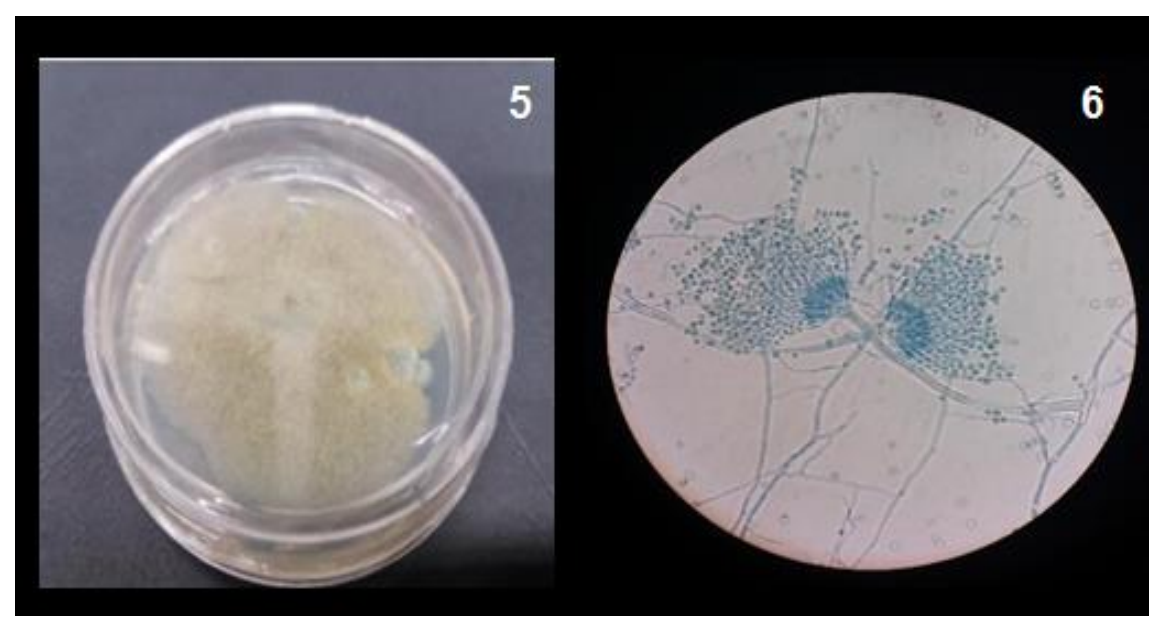

Fig. 5. Morfotipo macroscópico obtenido en medio de cultivo PDA de un hongo filamentoso típicamente reportado en estudios de suelo, Aspergillus spp.

Fig. 6. Morfotipo microscópico obtenido en medio de cultivo PDA (luego del proceso de purificación de la muestra mediante el 
crecimiento en microcultivo) de un hongo filamentoso típicamente reportado en estudios de suelo, Aspergillus spp.

\section{DISCUSIÓN}

Los organismos más predominantes encontrados en los resultados obtenidos están representados por los géneros Penicillium y Curvularia, aunque destacan de igual manera Aspergillus, Fusarium, Geotrichum, Pythium y Cladosporium lo cual coincide con lo expresado con el estudio realizado por Arias \& Piñeros (2008), que señalan que "La población fúngica encontrada pertenece a los siguientes géneros: Alternaria, Aspergillus, Cladosporium, Curvularia, Fusarium, Penicillium, Rhizopus y Trichoderma; siendo los géneros de mayor incidencia Aspergillus, Penicillium y Curvularia", adicional al estudio previamente señalado, los resultados coinciden de igual manera con la investigación realizada por Estrada \& Julio (2017).

Con base a las observaciones de morfotipos macroscópicos y microscópicos pudimos identificar de manera clara y precisa los principales géneros de hongos filamentosos de las muestras obtenidas.

Los hongos son organismos sumamente exitosos y vitales en el desarrollo de la vida sobre la tierra, teniendo inclusive la capacidad de habitar y desarrollarse sobre roca desnuda. En su mayoría son beneficiosos para el hombre, ya que se encargan de degradar la materia orgánica compleja convirtiéndola a formas químicas simples que pasan a formar parte del suelo, donde finalmente son absorbidas por otras generaciones de plantas, encargándose en gran medida de la fertilidad de la tierra (García, 2012); pese a los perjuicios que pueden causar estos organismos a los seres vivos, incluyendo a los humanos, son un grupo de organismos muy importantes y exitosos desde el punto de vista evolutivo trascendental para el desarrollo de la vida en el planeta.

Los hongos no esporulados (micelio estéril) son difícilmente identificables, esto se debe a que los mismos no han generado las estructuras que permiten su efectiva identificación. Para tal motivo 
es necesario entonces realizar pruebas utilizando diversos medios de cultivo (agar Suelo, agar Papaya, agar Extracto de Malta, agar Sabouraud, etc.) los cuales permitirán crear las condiciones óptimas de crecimiento del hongo, permitiendo así que el mismo genere las estructuras que conduzcan a su efectiva identificación.

El área que mayor diversidad presentó (en número y especies), está representada por el vientre, seguido de la cloaca lo cual sin duda era de esperar, ya que dichas áreas son las que predominantemente están en contacto con el suelo, nutriéndose continuamente del resultado de esta relación directa (organismo, habitad).

El medio de cultivo que proporcionó mejores resultados estuvo representado por el agar Papa Dextrosa (PDA), seguido por el agar V8, siendo estos los que mayor y mejores resultados (en calidad y cantidad de muestras) proporcionaron a nuestra investigación.

\section{CONCLUSIONES}

Los datos obtenidos indican, que los géneros más representativos de la micobiota encontrada en el muestreo realizado está representado por dos géneros (Penicillium y Curvularia), los cuales están asociados o vinculados a estudios típicamente encontrados en muestras de suelo.

La utilización de métodos de microbiología clásica, han permitido la identificación efectiva de los principales géneros de hongos filamentosos presentes en los organismos y las áreas muestreadas.

Ambos grupos serpientes y hongos son organismos estigmatizados a lo largo del tiempo, esto ha provocado que se devalúe su importancia en los procesos biológicos, los cuales incluyen desde el control de poblaciones de roedores, hasta la degradación de la materia orgánica para su posterior utilización en los ciclos biogeoquímicos; que día tras día promueven el avance o progreso de la vida en el planeta.

Esta investigación pionera en nuestro país, sienta las bases metodológicas para futuros estudios en el Centro para 
Investigaciones y Respuestas en Ofidiología de la Universidad de Panamá (CEREO), que permitan ampliar el conocimiento en cuanto a la relaciones que mantienen los ofidios con otros grupos de organismos y su importancia para la generación de nuevos conocimientos en el área de la zoología, ecología y la micología, entre otras.

\section{AGRADECIMIENTO.}

Los autores agradecen en su investigación sobre la micobiota presente en serpientes al Centro para Investigaciones y Respuestas en Ofidiología de la Universidad De Panamá (CEREO), quienes gentilmente contribuyeron con los organismos objeto de este estudio. Adicional a esto a la Universidad de Panamá (Facultad de Ciencias Naturales Exactas y Tecnología), Departamento de Microbiología y Parasitología, por su gentileza en el suministro de los equipos y materia prima para la realización de esta investigación, inédita para nuestro país.

\section{REFERENCIAS}

Arenas, R. 1993. Micología Médica ilustrada. Clínica, laboratorio y terapéutica. Primera edición. McGraw Hill. México D.F. 352 pp.

Arenas, R. 2003. Micología Médica ilustrada. Segunda edición. McGraw Hill. México D.F. 352 pp.

Arias; Edna, Piñeros Paola. 2008. Aislamiento e Identificación de Hongos Filamentosos de muestras de Suelo de Los Paramos de Guasca. Tesis para optar por el Titulo de Microbiología Industrial, Universidad Pontificia Javeriana, Bogotá Colombia. 170-pp

Bills GF, Christensen M, Powell M, Thorn G. Saprobic soil fungi. p. 271-302, In G.M. Mueller, G.F. Bills, and M.S. Foster (Eds.). Biodiversity of Fungi: Inventory and Monitoring Methods. Elsevier Academic Press, San Diego, CA. 2004. p. 777. 
Bonifaz Trujillo, J. A. 2012. Micología Médica Básica. Cuarta edición. McGraw - Hill Interamericana Editores, S.A. de C.V. México D.F. 583 pp.

Bonifaz Trujillo, J. A. 2015. Micología Medica Básica. Quinta edición. Disponible en http://accessmedicina.mhmedical.com/book. Consultado el 15 de febrero de 2018.

Calvo Torras, Ma. A, Girmé Vila,G, Grau Noguer, E; Arosemena Angulo, E. 2014. Especial Hongos Filamentosos y Levaduras. Revista de la Sociedad Española de Microbiología, 57:1-84 pp.

Casas, G. 1989. Micología General. Ediciones de la Biblioteca. Caracas, Venezuela. 488 pp.

Curiel, Jorge. Los microorganismos, esenciales para la vida en el planeta. 2016. Revista del Museo Nacional de Ciencias Naturales. http://naturalmentemncn.org/los-microorganismos-esenciales-parala-vida-en-el-planeta/ Consultado el 1 de febrero del 2018.

Davis, A. S. La serpiente en las Culturas Ancestrales. Disponible en https://reydekish.com ～/2013/10/09/la-serpiente-en-las-culturas ancestrales/ Consultado el 10 de enero de 2018.

Dunn, E. R. 1944. Los géneros de anfibios y reptiles de Colombia III. Caldasia. Vol. III. 3 (12) 155-244 pp.

Fernández P, R. 2017. Importancia de las Serpientes. http://www. serpientepedia.com/importancia-de-las-serpientes/. Consultado el 15 de enero del 2018.

Fuentes, R. D. and G. Corrales. 2016. New distribution record and reproductive data for the Chocoan Bushmaster, Lachesis acrochorda (Serpentes: Viperidae), in Panama. Mesoamerican Herpetology 3: 115-127.

García H, Flor Teresa. Hongos. http://www.florgarcia.com/wpcontent/uploads/2012/10/HONGOS-Generalidades-metabolismoreproduccion-clasificacion.pdf. Consultado el 15 de enero del 2018. 
Guzmán GS, Gómez-García O, Rodríguez-García AJ, Luna-Morales N. Mordeduras de serpientes venenosas en Veracruz. I Reunión de Herpetología Villahermosa, Tabasco México 1990.

Hawksworth, David L. The magnitude of fungal diversity: the 1.5 million species estimate revisited. Mycological Research. 2001. Vol 105 (12). Pp 1422-1432.

Hsiang, Allison. 2015. The origin of Snakes. BMC Evol Biol. 2015. Disponible en: https://www.ncbi.nlm.nih.gov/pubmed/25989795. Consultado el 18 de noviembre de 2017.

Khöler, Gunther; Reptiles of Central America; 2003. Piter Stafford, London; pp 369.

Maryuri, Y. Estrada A, Rachel, E. Julio, J. Aislamiento $e$ identificación de la Micobiota en Suelos de cultivos de Tomates en la Península de Azuero, Panamá. Tesis para optar por la Licenciatura en Biología. Universidad de Panamá. República de Panamá 2017.

Mayo García, J. 2018. Importancia de los Hongos en la Biodiversidad. Consultado el 31 de enero de 2018. Disponible en http://www.avilabierta.com/PDF/textos/4/hongosybiodiversidad.pd $\mathrm{f}$

Ordaz, D., Salazar, A. Análisis de Varianza. Disponible en: https://es.slideshare.net/salazaraez/anlisis-de-varianza-43374041 Consultado el 12 de diciembre del 2017.

Kirschner, R, Piepenbring, M. New species and records of cercosporoid hyphomycetes from Panamá. Mycological Progress. 2006. 5(4). pp 207-219.

Piepenbring, M; Hofmann, T.A; Kirschner, R; Mangelsdorff, O, Perdomo, D, Rodríguez, J, Tramp,T. Diversity Patterns of Neotropical Plants Parasitic Microfungi. Ecotropica. 2011. 17: pp 27-40.

Piepenbring, M. 2015. Introducción a la Micología en los Trópicos. St. Paul Minnesota. American Phytopathological Society. 366 pp. 
DOI New species and records of cercosporoid hyphomycetes from Panama.

Pontón, J., Moragues, Ma. D.; Gené, J.; Guarro, J., Quindós, G. 2002. Hongos y Actinomicetos alergénicos. Revista Iberoamericana de Micología. 1:51 pp.

Suarez, G. Luisa F . 2017. Reptiles y Anfibios como Bioindicadores para implementar en Estudios de Impacto Ambiental y Planes de Manejo Ambiental. Trabajo de grado. Universidad Militar Nueva Granada. Trabajo de Grado. Bogotá D.C. Colombia. pdf

Tejeira, M, 1994. Utilidad Económica actual y Potencial de las Serpientes. Universidad de Panamá.

Watanabe, T. 2010. Pictorial Atlas of Soil and Seed Fungi Morphologies of Cultured Fungi and Key to Species. Third Edition. Taylor and Francis Group, LLC. 397 pp.

Sitio web:

Anónimo. (S.F) c. Venenos que curan. Consultado el 12 de noviembre de 2017.

Anónimo. (S.F) d. Reptiles Diápsidos. Disponible en: reptiles.tautera.com/reptiles-diapsidos/. Consultado el 19 de noviembre de 2017.

Anónimo. (S.F) e. Leofilizador. Disponible en: https://www.uam.es./otros/novalind/liofilizador.htm. Consultado el 19 de noviembre de 2017.

Anónimo. (S.F) f. Control biológico de plagas y enfermedades vegetales. 6/12/17. Disponible en: https://sgittotri.ua.es/es/empresa/documentos/ot-0811-control-biologico-deplagas.pdf Consultado el 6 de diciembre de 2017.

Anónimo. (S.F) h. Impacto del cambio climático sobre anfibios y reptiles. 2016. Consultado el: 20/11/17. Disponible en: http://www.ambientum.com/boletino/noticias/Impacto-del-cambioclimatico-sobre-anfibios-y-reptiles.asp Consultado el 11 de noviembre de 2017 
Serpientepedia (2019), Enciclopedia Digital Especializada en Serpientes. http://www.serpientepedia.com/importancia-de-lasserpientes/

Recibido 13 mayo 2019, y aceptado el 16 noviembre 2020. 